\title{
«У СЛЫШАЩИХ БОЛЬШЕ ВОЗМОЖНОСТЕЙ ДЛЯ ЖИЗНИ»: ПРОБЛЕМЫ СРЕДНЕГО ПРОФЕССИОНАЛЬНОГО ОБРАЗОВАНИЯ ГЛУХИХ И СЛАБОСЛЫШАЩИХ
}

Статья посвящена изучению проблем, с которыми сталкиваются глухие и слабослышащие учащиеся в процессе получения среднего профессионального образования. В качестве базы для анализа выступил всероссийский опрос глухих и слабослышащих, обучающихся в колледжах и ПТУ, проведенный в формате очного анкетирования, а также 21 полуформализованное интервью с учащимися и экспертами. Изменения, происходящие в профессиональной подготовке глухих и слабослышащих в последние годы (введение инклюзивного образования, расширение перечня доступных профессий), с одной стороны, открывают перед людьми с инвалидностью по слуху новые возможности, а с другой, требуют пересмотра основных подходов к работе с данной группой. Это влечет за собой появление проблем, характерных для любого переходного периода, несмотря на то, что история профессионального образования людей с нарушениями слуха в России насчитывает более 200 лет и на сегодняшний день стратегия получения среднего профессионального образования является основной для молодежи с нарушениями слуха, причем решение о поступлении носит, как правило, продуманный характер. Основной проблемой, о которых говорят сами учащиеся, является узкий коридор возможностей выбора специальности, сужаемый в ряде случаев искусственно из-за стремления колледжей объединить всех глухих учащихся на одном направлении, а также из-за неготовности колледжей работать с данной группой. Проблемными видятся информантам наличие административного барьера и необходимость получения индивидуальной программы реабилитации и абилитации, определяющей индивидуальные ограничения при приеме на работу. Информанты говорят о низком качестве школьного образования, отмене льгот, нехватке

Никита Викторович Большаков- ст. преподаватель, департамент социологии, Национальный исследовательский университет «Высшая школа экономики», Москва, Россия. Электронная почта: nbolshakov@hse.ru 
переводчиков жестового языка и недостаточной готовности педагогов работать с глухими и слабослышащими. Однако наиболее серьезные трудности информанты связывают с отсутствием карьерных перспектив и механизмов институциализированной поддержки трудоустройства глухих через колледж или другие организации.

Ключевые слова: глухие, слабослышащие, среднее профессиональное образование, инклюзивное образование, профессиональный выбор

DOI: 10.17323/727-0634-2019-17-4-571-584

Изменения в сфере образования затронули и специальное образование. Подписанная и ратифицированная Россией в 2012 г. Международная конвенция ООН о правах инвалидов призывает пересмотреть основные подходы к анализу инвалидности, что выводит на первый план вопросы не столько поддержки людей с ограниченными возможностями здоровья, сколько активизации потенциала каждого индивида, в том числе за счет институтов образования и занятости. При этом особые подходы должны быть разработаны для людей с различными формами инвалидности, так как рассмотрение людей с инвалидностью как гомогенной группы с общими запросами приводит к игнорированию их социокультурных особенностей и уникальных потребностей. Одной из таких групп являются глухие и слабослышащие, специфическими чертами которых выступают использование жестового языка, культура глухих и другие особенности, накладывающие серьезные ограничения на возможности их успешной профессиональной адаптации.

В настоящий момент специализированное обучение переживает переходный период и трансформируется вследствие принятия нового закона «Об образовании». В последние годы основные опасения родителей и представителей сообщества глухих связаны с внедрением инклюзивного образования, которая должна была прийти на смену коррекционных школ. Активисты высказывались против закрытия коррекционных школ, а в некоторых регионах состоялись митинги за сохранение ситуации с образованием детей с инвалидностью (Бойцов 2013; Лемуткина 2015). Однако позже от «насильственной инклюзии» отказались, так как по мнению ряда чиновников, «непродуманное и неподготовленное закрытие коррекционных классов и учреждений может привести к необратимым последствиям для здоровья и развития больных детей» (РИА Новости 2015). На сегодняшний день родители детей с нарушениями слуха имеют возможность выбора: отдавать ребенка в инклюзивную школу или в специализированную, однако процесс реформирования специализированного образования еще не завершен.

Возможность выбора инклюзивной формы обучения предоставляется глухим и слабослышащим не только во время обучения в школе, но и на этапе 
получения профессионального образования. На 2015 г. в 68 образовательных организациях среднего профессионального образования обучались 1403 инвалида по слуху, а в 112 образовательных организациях высшего профессионального образования- 884 (Письмо Минобрнауки РФ 2015). В то же самое время общее число студентов высших учебных заведений в России (Бородина и др. 2017) составляло 4766 тыс., тогда как в образовательных организациях среднего профессионального образования обучались 686 тыс. Таким образом, выбор образовательной траектории не является одинаковым для глухих и слышащих. Если первые в 1,6 раз чаще делают выбор в пользу среднего профессионального образования, то вторые значимо чаще выбирают траекторию, предполагающую получение высшего образования, что говорит о высокой популярности среднего профессионального образования среди глухих и слабослышащих.

Предлагаемый анализ посвящен выделению ключевых факторов, определяющих профессиональный выбор глухой и слабослышащей молодежи (фокус будет сделан на проблемах и барьерах), а объектом выступили карьеры глухих и слабослышащих с различной степенью потери слуха. Участниками анализа стали люди, проживающие в Москве и других регионах России в возрасте от 16 до 30 лет, обучающиеся в учреждениях среднего профессионального образования и имеющие ограничения по слуху. Исследование базируется на принципах смешивания методов и включает в себя два этапа, количественный и качественный, выполненных параллельно. В ходе количественного опроса реализована доступная целевая выборка с применением смешанной процедуры отбора респондентов. Отсутствие статистических данных о ключевых параметрах генеральной совокупности, а также в целом о числе глухих и слабослышащих в России и в частности о характеристиках представителей интересующей возрастной группы, являющееся результатом непрозрачности выстроенной статистики инвалидности (Малева 2017:248), не позволяет построить репрезентативную в статистическом смысле выборку, что должно быть обозначено, как ограничение исследования. Общий объем выборки составил 187 человек.

В статье представляется анализ качественной части исследования. В основе выборки на качественном этапе также лежал принцип достижения максимальной представленности информантов, обладающих различными характеристиками. В этом случае важно достичь разнообразия по таким параметрам, как пол, курс обучения, специальность, город проживания, степень потери слуха и владение жестовым языком. Кроме того, дополнительно проведен ряд экспертных интервью со специалистами в области профессионального образования глухих и слабослышащих из разных сфер. Общий объем выборки качественного этапа составил 21 интервью (5 экспертных интервью и 16 интервью с учащимися), часть из которых взята при помощи переводчика жестового языка. 


\section{Проблемы среднего профессионального образования глухих и слабослышащих}

На протяжении продолжительного периода ситуация с получением глухими и слабослышащими профессионального образования менялась (Базоев 1999). Распад Советского Союза ознаменовался ухудшением общего положения дел в сфере трудоустройства глухих, а также принятием ряда нормативных актов, усугубляющих сложившуюся ситуацию. В последние годы в сфере качественного предоставления инвалидам по слуху высшего и среднего профессионального образования стали происходить положительные изменения. Так, например, государственная программа «Доступная среда» на 2016-2020 гг. впервые включает в себя разделы, посвященные профессиональному образованию людей с нарушениями слуха, в частности, вопросам перевода лекций на жестовый язык и приспособления программ к потребностям и особенностям глухих и слабослышащих. По данным Всероссийского общества глухих, полученным от Минобрнауки РФ (Из интервью: Мужчина, начальник отдела ВОГ), на 2016 г. фактическая подготовка глухих и слабослышащих велась по 74 специальностям из 333 рекомендованных Министерством труда России (Приказ Минтруда РФ 2014), а из 89 регионов Российской Федерации только в 56 имелись образовательные организации, обучающие инвалидов по слуху. Можно предположить, что за последующие годы число доступных профессий увеличилось, однако представители учебных заведений профессионального образования, в которых в настоящее время ведется обучение глухих и слабослышащих, свидетельствуют об отсутствии конкурса или о недоборе студентов на многие специализированные программы. В то же время сами глухие и слабослышащие заявляют о различных юридических и институциальных барьерах, мешающих получению качественного образования и трудоустройству.

Таким образом, трансформации, происходящие с профессиональной подготовкой глухих и слабослышащих (введение инклюзивного образования, расширение перечня доступных профессий, принятие новых стандартов, изменение правил приема и обучения глухих и слабослышащих), с одной стороны, открывают перед людьми с инвалидностью по слуху новые возможности, а с другой, становятся барьером на пути профессиональной адаптации и вызовом, в том числе в условиях пересмотра подходов к работе с глухими и слабослышащими. Необходимо понимать, с какими проблемами сталкиваются учащиеся с нарушениями слуха, делающие выбор в пользу профессионального образования, какие барьеры затрудняют процесс его получения.

Согласно нашим данным, получение профессионального образования является одной из ключевых стратегий у глухой и слабослышащей молодежи, причем почти $60 \%$ учащихся говорят о том, что решение учиться 
в конкретном колледже принято ими более чем за полгода, что говорит о продуманности выбранной стратегии. Тем не менее даже учащиеся колледжей и ПТУ, заранее выбравшие место учебы и поступившие в желаемое учебное заведение, говорят о барьерах и трудностях, с которыми им приходится сталкиваться в процессе обучения. Проблемы профессионального образования глухих и слабослышащих интересовали нас в данном исследовании в качестве одного из факторов, определяющих возможности профессионального выбора молодежи, хотя именно момент профессионального выбора, опосредованный различными личностными и структурными характеристиками, является одним из ключевых этапов в жизни и карьере любого человека (Brown 2002; Kerckhoff 1996: 37-56). Эти проблемы приводят к появлению различных барьеров, препятствующих полноценной трудовой адаптации глухих и слабослышащих. Так, на пути профессиональной адаптации становится узкий коридор возможностей на всех этапах построения профессиональной траектории, начиная от зачисления в школу, выбора колледжа и специальности, заканчивая поиском работы и трудоустройством:

Если бы я была слышащей, то, стопудово бы имела больше возможностей. Например, участвовать в разных мероприятиях, ездить на международные лагеря <... . Да и не только, бизнесом бы точно занялась $100 \%$ (ж., 18 лет, Москва).

В ходе интервью информанты отмечают, что некоторые специальности оказываются для них закрытыми, поэтому выбор приходится делать из ограниченного числа направлений. Границы этого коридора задаются естественным образом из-за того, что работа по определенной профессии оказывается недоступна глухому, зачастую он сужается искусственно. Особую роль в сужении профессиональных возможностей играют сами колледжи, не давая возможности молодым людям с инвалидностью по слуху выбирать специальности из предложенных для слышащих. Представители колледжей отмечают, что брать на работу переводчика ради одного учащегося нецелесообразно и нерационально, поэтому администрация старается по возможности собирать всех глухих и слабослышащих в рамках одного направления, чтобы они посещали одни и те же занятия:

Мы не имеем права отказать глухим в приеме, но и тут такая ситуация. Если будет один человек, то ради него нанимать переводчика... Поэтому мы их переориентируем на специальности, где есть переводчики (ж., педагог и переводчик в инклюзивном колледже).

Второй проблемой является административный барьер, который может проявляться в нескольких формах: во-первых, в соответствии с последними положениями, дети с инвалидностью так же, как и остальные абитуриенты, должны сдавать вступительные экзамены; во-вторых, 
абитуриенты обязаны предоставлять различные документы, проходить медико-социальную экспертизу (MCЭ) и получать индивидуальную программу реабилитации и абилитации (ИПРА). Вступительные экзамены должны быть организованы «с учетом особенностей психофизического развития, индивидуальных возможностей и состояния здоровья» (Приказ Минобрнауки РФ 2014). Например, таким учащимся может быть предоставлено дополнительное время на выполнение заданий или физическая помощь в ходе экзамена, однако учащиеся коррекционных и специализированных учебных заведений даже в специально созданных условиях не всегда способны выполнять задания наравне со слышащими из-за нехватки знаний и навыков. Низкий уровень подготовки, являющийся во многом результатом низкого качества школьного образования глухих, ранее не мешал молодежи с нарушениями слуха получать профессию и устраиваться в жизни, но в связи с отменой части льгот при поступлении, пути трудовой реализации оказываются ограничены. Причем необходимость участвовать в общем конкурсе в данном случае усугубляется низкой правовой грамотностью молодежи с инвалидностью (Баскакова и др. 2012: 147):

Отменили же льготы для поступления для глухих. Вот. И они на общих основаниях поступают. Наш директор принял решение, что группы будут инклюзивные вместе со слышащими. И поэтому все на общих основаниях поступают (ж., педагог и переводчик в инклюзивном колледже).

В целом, низкий уровень школьного образования, не позволяющий глухим и слабослышащим строить желаемую траекторию, в качестве проблемы профессионального образования очень часто фигурировал в нарративах информантов. Сами учащиеся склонны оценивать качество полученного ими в школе образования, как низкое, что, по их мнению, не позволяет им не только получать высшее образование, но и поступить в хороший колледж на желаемую специальность, а также препятствует дальнейшему успешному трудоустройству:

Глухие не могут устроиться на работу, им это тяжело дается, потому что у многих нет образования. <..> Моя мама говорит, что сейчас в XXI веке никому не нужен глухой человек без образования на работе (ж., 20 лет, Москва).

Отдельное внимание информанты уделяли индивидуальным программам реабилитации и абилитации, которые зачастую выступают барьером к трудоустройству глухих и слабослышащих на индивидуальном уровне. ИПРА выдается бюро медико-социальной экспертизы и содержит в себе информацию о программе медицинской реабилитации инвалида (восстановительной терапии, необходимых технических средствах медицинской реабилитации, санаторно-курортном лечении), о программе социальной реабилитации (оказании юридической помощи, социокультурной 
и психологической реабилитации, информировании и консультировании по вопросам реабилитации), а также о психолого-педагогической реабилитации для детей младше 18 лет. Трудности прохождения МСЭ и получения ИПРА связаны с тем, что помимо информации о необходимости различных видов терапии и хирургии, технических средствах реабилитации, и программах лечения, ИПРА содержит также раздел «Профессиональная реабилитация», который включает в себя информацию о профессиональной ориентации, профессиональном обучении и переобучении, содействии в трудоустройстве и производственной адаптации. Помимо прочего, в ИПРА включаются рекомендации по трудоустройству, доступные виды труда и трудовые действия (функции), выполнение которых затруднено, а в своих заключениях специалисты МСЭ опираются на существующее законодательство, однако его трактовка сильно зависит от специалистов, принимающих решение. То есть, если в ИПРА будет указано, что человеку с инвалидностью недоступны определённые виды труда (например, труд, требующий общения с другими людьми), или рекомендуется создание особых условий труда (например, изолированное помещение), то большой перечень возможных специальностей будет для него закрыт.

Как отмечают эксперты, «любые рекомендации в этой графе необязательны к исполнению людьми с инвалидностью. Но они обязательны для работодателя» (РООИ Перспектива 2017), соответственно получение работы становится для глухого или слабослышащего человека затруднительным. Кроме того, врачи могут вписать в ИПРА такие нечеткие ограничения, как работа на позициях, не требующих общения с людьми, тем самым очень сильно ограничив возможности трудоустройства глухого или, например, в раздел «профессиональное обучение» врачи без согласия клиента могут вписать конкретные виды работ, тем самым давая основания для отказа в приеме на любую другую специальность (не указанную в ИПРА). В ряде случаев в ИПРА вписываются конкретные специальности или профессии, которые рекомендуются ребенку с инвалидностью, однако важно учитывать, что ИПРА выдается бюро медико-социальной экспертизы, не обладающим необходимыми знаниями о ребенке для совершения подобных профориентационных заключений:

Хотела после училища поступать в техникум для повышения квалификации, но раньше медкомиссия не давала разрешение на учебу, т.к. у меня 3-я группа инвалидности. И по ихнему учебнику-не положено (ж., 30 лет, Ярославль).

Кроме того, прохождение врачебно-трудовой медицинской комиссии и подготовка соответствующих документов может занимать продолжительное время, из-за чего возникает ситуация, когда информанты просто не успевают получить все необходимые справки до окончания срока подачи документов в учебное заведение и вынуждены ждать целый год, 
выбирать альтернативные варианты учебы, не соответствующие их желаниям или вовсе отказываться от данной траектории: «[не успела поступить, так как] Приехала в Москву, нужно было все справки получать, ВТЭК» (ж., 18 лет, Москва).

Информанты отмечают, что сталкиваются с рядом иных формальных трудностей, не позволяющих им получить желаемую специальность: необходимость регистрации при подаче документов, а также различия в доступе к ресурсам для людей с инвалидностью в разных регионах значительно снижают их жизненные шансы и сужают коридор доступных карьерных и профессиональных возможностей:

На самом деле, во время 9 класса я хотела на бухгалтера пойти учиться. $<\ldots>$ У меня действительно не было никакого желания оставаться в школе учиться, и я стала изучаться разные колледжи для бухгалтеров, но там требовалась регистрация (ж., 23 года, Москва).

Серьёзной проблемой, мешающей учащимся с нарушениями слуха получать качественное профессиональное образование является отсутствие специальных условий, и в первую очередь квалифицированного перевода на жестовый язык в учебных заведениях, тогда как его использование в дополнение к устной речи положительно влияет на понимание учебного материала (Варинова, Траулько, 2011:22), позволяет сделать информацию более доступной и удобной для восприятия. Образовательная организация должна предоставить возможность получения услуг перевода (Варинова, 2017: 16), однако многие колледжи, в которых обучаются один или несколько глухих, не могут позволить себе содержать в штате переводчика, либо вынуждены обращаться к переводчикам, не обладающим необходимым юридическим статусом, дипломом, подтверждающим квалификацию. Даже если переводчик в штате все же присутствует, в обстоятельствах, когда студенты с нарушениями слуха учатся в разных группах, обеспечение постоянного сопровождения на всех занятиях становится невозможным. Возникают ситуации, когда студенты оказываются вынуждены сами находить себе переводчика, однако индивидуально (по ИПРА) человек с инвалидностью по слуху может претендовать на 40 часов работы переводчика в год, что, естественно, недостаточно для получения качественного образования, а также не позволяет добиться высокого качества перевода, так как, лекции, семинары и любые занятия подразумевают использование специальной лексики, не знакомой или слабо знакомой приглашенному переводчику. Как уже было отмечено выше, в ряде колледжей данная проблема решается за счет объединения глухих в рамках одной учебной программы или направления, что, по сути, лишает их возможности выбора специализации:

...там хорошо обучались не только жестовому языку, но и дактилю, благодаря которому я мог воспринимать материал. Половина учителей знала дактиль, другая - нет < .. > Иногда я могу говорить голосом и читать 
по губам, но большинство людей плохо говорят, у них плохая артикуляция (м., 20 лет, Москва).

Следующей проблемой профессионального образования является нехватка квалифицированных педагогов, умеющих работать с глухими и слабослышащими. Работа с учащимися с нарушениями слуха требует от преподавателей применения специализированных методик и подходов (Антонова и др. 2017), однако проводимое обучение зачастую носит формальный характер, из-за чего педагоги просто не понимают, как работать с такими учащимися. Кроме того, внедрение инклюзивного образования наталкивается на сопротивление со стороны педагогов, которые просто не готовы перестраивать формат занятий и переориентировать их на включение глухого учащегося в работу: «Не все преподаватели готовы как-то перестраивать уроки. Это же адаптированные программы должны быть для них» (ж., педагог и переводчик в инклюзивном колледже, Москва).

Наконец, наиболее серьезной проблемой профессионального образования глухих является то, что карьерные перспективы вызывают у большинства учащихся опасения: по результатам нашего опроса, в том, что поиск работы не составит большого труда уверены только $25 \%$ респондентов, тогда как 3/4, наоборот, предполагают, что поиск работы займет длительное время. Что показательно, хуже всего свои перспективы оценивают те, кто в процессе обучения имел (или продолжает иметь) временную подработку. То есть к этому числу принадлежат учащиеся, которые имеют представление о рынке труда, возможно, уже искали свободные позиции, но не смогли получить стабильное место работы. Кроме того, юноши значимо чаще придерживаются пессимистичных взглядов относительно ситуации на рынке труда: $80 \%$ среди них уверены, что им будет трудно найти подходящую работу по окончанию колледжа, тогда как среди девушек эта доля составляет $67 \%{ }^{1}$.

Даже если после получения профессионального образования молодым людям удается получить работу- это, как правило, низкоквалифицированный, тяжелый труд, не позволяющий сделать карьеру или заработать. В качестве основных возможностей для трудоустройства называются заводы и крупные торговые компании. Менеджерская или офисная сфера воспринимается информантами как недоступная глухим. Рассказывая о потенциальных местах работы, информанты большое внимание уделяют тому, что для глухих доступен именно ручной труд. В своих нарративах они подчеркивают тот факт, что любая работа, которая сейчас предлагается глухим и слабослышащими на рынке-это в первую очередь работа руками, которая далеко не всегда соответствует получаемому образованию (возможности трудоустройства глухих по таким популярным среди них направлениям обучения, как дизайн, стоматологическая ортопедия, лабораторная диагностика, программирование

\footnotetext{
${ }^{1}$ Во всех случаях критерий Хи-квадрат значим на уровне доверительной вероятности $95 \%$.
} 
и др. оказываются ограничены). Ожидания от уровня оплаты труда, а также карьерного роста также не добавляют учащимся оптимизма: информанты, имеющие опыт работы, говорят о несправедливой разнице в оплате труда слышащих и глухих. Они отмечают, что даже на аналогичных позициях, выполняя одинаковый объем работ, глухие все равно в ряде случаев получают более низкую заработную плату:

Нет, то есть на шоколадной фабрике я работала. Во-первых, тяжело было с графиком: 2 через 2. Плюс зарплата была очень маленькая. Большая разница в доходах. Слышащие, конечно, больше получают. Глухие гораздо меньше. Там [на другой работе] тоже есть большая разница в зарплате между мной и слышащими (ж., 23 года, Москва).

При этом, глухие и слабослышащие учащиеся не надеются на помощь учебного заведения при поиске работы: меньше 1/3 опрошенных указали, что колледж может помочь им с трудоустройством, а менее 1/4 предполагают, что с поиском работы им может помочь служба занятости:

Они были удивлены тем, что после окончания им не помогали устраиваться на работу. Глухим приходилось самостоятельно искать работу, но, увы, компании отказывали из-за их глухоты. Ребята обучались впустую. И несмотря на диплом, им пришлось устраиваться на завод, в магазин (м., 20 лет, Москва).

То есть вопрос трудоустройства в большинстве случаев должен решаться индивидуально, через друзей, знакомых и родственников (49\%) или через объявления (30\%): практически отсутствуют механизмы институциализированной поддержки трудоустройства глухих.

\section{Заключение}

Несмотря на многолетнюю традицию обучения глухих и слабослышащих профессиональным навыкам, преждевременно говорить о том, что среднее профессиональное образование людей с инвалидностью устроено оптимальным образом. Происходящие изменения в совокупности с трансформацией взглядов на инвалидность и подходов к работе с людьми с инвалидностью, привели к появлению новых и актуализации уже имеющихся проблем среднего профессионального образования глухих и слабослышащих.

В целом, стратегия получения среднего профессионального образования является основной для молодежи с нарушениями слуха, причем решение о поступлении носит, как правило, продуманный характер. Тем не менее учащиеся говорят о ряде проблем в этой области, основной из которых является узкий коридор возможностей выбора специальности, сужаемый в ряде случаев искусственно из-за стремления колледжей объединить всех 
глухих учащихся на одном направлении, а также из-за неготовности колледжей работать с данной группой. Кроме того, важную роль играет административный барьер, заключающийся в необходимости получения индивидуальной программы реабилитации или абилитации, выдаваемой бюро медико-социальной экспертизы и определяющей, помимо прочего, индивидуальные ограничения при приеме на работу. Таким образом, ИПРА ограничивает возможность выбора профессии наравне с действующим перечнем противопоказаний Минздравсоцразвития, запрещающим работу глухих по ряду популярных направлений. В дополнение к этому низкое качество школьного образования глухих не позволяет им участвовать во вступительных испытаниях на общих основаниях в условиях отмены льгот при поступлении.

Проблемами, с которыми глухие учащиеся сталкиваются непосредственно в процессе обучения в колледже, становится нехватка переводчиков жестового языка (или даже их отсутствие), необходимость специальных условий и отсутствие соответствующих ресурсов у учебного заведения, а также низкий уровень подготовки педагогов. Наконец, информанты отмечали, что получение профессионального образования не является гарантией дальнейшего трудоустройства. Плохие карьерные перспективы и нехватка рабочих мест, пригодных для глухих и слабослышащих, заставляют молодежь отказываться от выбранной траектории получения среднего профессионального образования в пользу альтернативных вариантов. Проблемным информантам видится и то, что вопрос трудоустройства должен решаться индивидуально: отсутствуют механизмы институциализированной поддержки трудоустройства глухих через колледж или другие организации, что отмечают как сами учащиеся, так и эксперты.

Важно отметить, что трудности и проблемы, выделенные в ходе исследования, могут носить неуниверсальный характер: по результатам аналогичных исследований именно люди с инвалидностью по слуху или зрению оказываются наиболее ограничены в возможностях получения дополнительного профессионального образования (Панченко, Кузнецова 2010: 73). Развитие инклюзивного образования позволит решить часть из указанных проблем, однако для формирования эффективных институтов профессиональной адаптации глухих необходима разработка комплексных программ, учитывающих конкретные условия реализации изменений на местах, а также потребности самих учащихся.

\section{Список источников}

Антонова О.А., Борякова Н. Ю., Богинская Ю. В., Коростелев Б. А., Котова Г. Л., Пискун О. Ю., Ромашкина В.Э., Руленкова Л.И., Соловьева И. Л., Тер-Григорьянц Р.Г., Майер В.Р., Швец Е.А. (2017) Учебное пособие по организачии обучения инвалидов по слуху в профессиональных образовательных организациях. Москва: СУВАГ. 
Базоев В.3. (1999) Становление и развитие системы профессионального образования глухих. Дис. канд. пед. наук. Москва: Институт коррекционной педагогики РАН.

Баскакова М.Е., Соболева В.И., Тодэ Н.О., Токсанбаева М.С., Чадова Т. А. (2012) Проблема доступности профессионального образования для лии с ограниченными возможностями здоровья в городе Москве. Москва: Международная Актуарная Компания.

Бойцов Д. (2013) Государство закроет коррекционные школь. Доступно по ссылке: http:/ www.gluxix.net/deafnews/sobitiya/4101-2013-01-14-20-15-51 (дата обращения: 2 октября 2018).

Бородина Д.Р., Гохберг О. Б., Жихарева О.Б., Забатурина И. Ю., Ковалева Г.Г., Ковалева Н.В., Кузнецова В.И., Озерова О.К., Шугаль Н.Б. (2017) Образование в цифрах: 2017: краткий статистический сборник. Москва: Высшая школа экономики.

Варинова О.А. (2017) Организация перевода на русский жестовый язык в профессиональном образовании. О. Л. Беляева, А.И. Картавцева (ред.) Русский жестовый язык: законодательство, исследования, образование. Красноярск: КГПУ им. Астафьева: 15-22.

Варинова О.А., Траулько Е.В. (2011) Сурдоперевод как необходимое условие качественного профессионального образования лиц с нарушением слуха. Современные исследования социальных проблем, 6 (2):21-23.

Лемуткина М. (2015) Чиновники пообещали сохранить специколы для детей-инвалидов. Доступно по ссылке: http://www.mk.ru/social/2015/11/22/chinovniki-poobeshhali-sokhranitspecshkoly-dlya-deteyinvalidov.html (дата обращения: 2 октября 2018).

Малева Т. М. (ред.) (2017) Инвалидность и социальное положение инвалидов в России. Москва: Дело.

Панченко О., Кузнецова И. (2010) Дополнительное профессиональное образование инвалидов как фактор их позиционирования в обществе на материалах Республики Татарстан. Журнал исследований социальной политики, 6 (1): 71-88.

Письмо Минобрнауки РФ (2015) На запрос Всероссийского общества глухих № 06-1039 от 04.09.2015 г.

Приказ Минобрнауки РФ (2014) Об утверждении Порядка приема на обучение по образовательным программам среднего профессионального образования № 36 от 23.01.2014 г.

Приказ Минтруда РФ (2014) Об утверждении методических рекомендачиях по перечню рекомендуемых видов трудовой и профессиональной деятельности инвалидов с учетом нарушенных функций и ограничений их жизнедеятельности № 515 от 04.08.2014.

РИА Новости (2015) Астахов: нельзя допускать закрытия коррекиионных школ. Доступно по ссылке: http://ria.ru/society/20150403/1056394627.html\#ixzz4AFcXD53z (дата обращения: 2 октября 2018).

РООИ Перспектива (2017) Чем помогает и мешает ИПРа при трудоустройстве? Доступно по ссылке: https://perspektiva-inva.ru/protec-rights/news/3860-2017-10-19-1515-07 (дата обращения: 2 октября 2019).

Brown D. (2002) Career Choice and Development. San Francisco: Wiley \& Sons.

Kerckhoff A.C. (ed.) (1996) Generating Social Stratification: Toward a New Research Agenda. Boulder: Westview Press. 


\title{
'THE NON-DEAF ENJOY MORE OPPORTUNITIES': THE PROBLEMS OF PROFESSIONAL EDUCATION FOR DEAF AND HEARING-IMPAIRED STUDENTS
}

\begin{abstract}
This article is dedicated to the study of problems faced by deaf and hearingimpaired students in the process of professional education. The analysis is based on the All-Russian survey of deaf and hearing-impaired students in colleges and professional schools. The study involved face-to-face interviews as well as 21 semi-formalized in-depth interviews with students and experts. The history of professional education of people with hearing impairments has more than 200 years in Russia. Today, the preferred strategy for young people with hearing impairments is to obtain a good secondary education and carefully plan out their career choice early. On the one hand, changes in the training systems available to deaf and hearing-impaired workers in recent years have opened up new opportunities. On the other hand, these changes require serious revisions to the main approaches in working with this group, which cause various problems common for any major transition. The main problem that students themselves mention is a narrow corridor of opportunities when choosing one's specialization. This narrowing occurs, in some cases, artificially due to universities' desire to unite all deaf students into one classroom. In other cases, universities are simply unwilling to work with the deaf. In addition, informants have to obtain an individual programme of rehabilitation or habilitation, which determines individual restrictions on admission to work. They also mentioned the low quality of school education, problems of certification in correctional educational institutions, the lack of sign language interpreters and low level of training of teachers. However, informants associate the most serious difficulties with the lack of career options and mechanisms for institutionalized support for the employment of deaf people through college or other organizations.
\end{abstract}

Key words: deaf, hearing-impaired, inclusive education, vocational education, career choice

DOI: 10.17323/727-0634-2019-17-4-571-584

\section{References}

Antonova O.A., Boryakova N. Yu., Boginskaya Yu.V., Korostelev B. A., Kotova G.L., Piskun O. Yu., Romashkina V.E., Rulenkova L.I., Solov'eva I.L., Ter-Grigor'yants R.G., Mayer V.R., Shvets E.A. (2017) Uchebnoe posobie po organizatsii obucheniya invalidov po slukhu v professional'nykh obrazovatel'nykh organizatsiyakh. [A Manual on the Organization of Training for People with Hearing Disabilities in Professional Educational Organizations]. Moscow: SUVAG.

Nikita Bolshakov- Senior Lecturer, School of Sociology, National Research University 'Higher School of Economics', Moscow, Russia. Email: nbolshakov@hse.ru 
Baskakova M.E., Soboleva V.I., Tode N. O., Toksanbaeva M.S., Chadova T.A. (2012) Problema dostupnosti professional'nogo obrazovaniya dlya lits s ogranichennymi vozmozhnostyami zdorov'ya v gorode Moskve [The Problem of Accessibility of Vocational Education for Persons with Disabilities in the City of Moscow]. Moscow: Mezhdunarodnaya Aktuarnaya Kompaniya. Bazoev V.Z. (1999) Stanovlenie i razvitie sistemy professional'nogo obrazovaniya glukhikh. [Formation and Development of the Vocational Education System for the Deaf]. Moscow: Institut korrektsionnoy pedagogiki RAN.

Boytsov D. (2013) Gosudarstvo zakroet korrektsionnye shkoly [The State will Close Correctional Schools]. Available at: http://www.gluxix.net/deafnews/sobitiya/4101-2013-01-14-20-15-51 (accessed 02 October 2019).

Borodina D.R., Gokhberg O. B., Zhikhareva O. B., Zabaturina I. Yu., Kovaleva G.G., Kovaleva N.V., Kuznetsova V.I., Ozerova O.K., Shugal' N.B. (2017) Obrazovanie v tsifrakh: 2017: kratkiy statisticheskiy sbornik [Education in Figures: 2017: A Brief Statistical Compendium]. Moscow: NRU HSE.

Brown D. (2002) Career Choice and Development. San Francisco: Wiley \& Sons.

Kerckhoff A.C. (ed.) (1996) Generating Social Stratification: Toward a New Research Agenda. Boulder: Westview Press.

Lemutkina M. (2015) Chinovniki poobeshchali sokhranit'spetsshkoly dlya detey-invalidov [Officials Promised to Retain Special Schools for Disabled Children]. Available at: http://www. $\mathrm{mk} . r u / s o c i a l / 2015 / 11 / 22 /$ chinovniki-poobeshhali-sokhranit-specshkoly-dlya-deteyinvalidov.html (accessed 2 October 2019).

Letter of the Ministry of Education and Science of the Russian Federation (2015) Na zapros Vserossiyskogo obshchestva glukhikh [to the Request of the All-Russian Society of the Deaf] N 06-1039 from 04.09.2015.

Maleva T.M. (ed.) (2017) Invalidnost' $i$ sotsial'noe polozhenie invalidov v Rossii [Disability and the Social Situation of Disabled People in Russia]. Moscow: Delo.

Order of the Ministry of Education and Science of the Russian Federation (2014) Ob utverzhdenii Poryadka priema na obuchenie po obrazovatel'nym programmam srednego professional'nogo obrazovaniya [On the Approval of the Procedure for Admission to Education in Educational Programs of Secondary Professional Education] N 36 from 23.01.2014.

Order of the Ministry of Labor of the Russian Federation (2014) Ob utverzhdenii metodicheskikh rekomendatsiyakh po perechnyu rekomenduemykh vidov trudovoy i professional'noy deyatel'nosti invalidov s uchetom narushennykh funktsiy i ogranicheniy ikh zhiznedeyatel'nosti [On the Approval of Methodological Recommendations for the List of Recommended Types of Labor and Professional Activities of Persons with Disabilities, Taking into Account Impaired Functions and the Limitations of Their Life Activity] N 515 from 04.08.2014.

Panchenko O., Kuznetsova I. (2010) Dopolnitel'noe professional'noe obrazovanie invalidov kak faktor ikh pozitsionirovaniya v obshchestve na materialakh Respubliki Tatarstan [Additional Vocational Education of Persons with Disabilities as a Factor in Their Positioning in Society on the Materials of the Republic of Tatarstan]. Zhurnal issledovaniy sotsial'noy politiki [The Journal of Social Policy Studies], 6 (1): 71-88.

RIA Novosti (2015) Astakhov: nel'zya dopuskat' zakrytiya korrektsionnykh shkol [Astakhov: The Closure of Correctional Schools Should Not Be Allowed]. Available at: http://ria.ru/society/20150403/1056394627.html\#ixzz4AFcXD53z (accessed 2 October 2019).

ROOI Perspektiva (2017) Chem pomogaet i meshaet IPRa pri trudoustroystve? [How does IPRA Help and Hinder Employment?]. Available at: https://perspektiva-inva.ru/protec-rights/news/3860 2017-10-19-15-15-07 (accessed 2 October 2019).

Varinova O.A. (2017) Organizatsiya perevoda na russkiy zhestovyy yazyk v professional'nom obrazovanii [Organization of Translation into Russian Sign Language in Vocational Education]. In: O.L. Belyaeva, A.I. Kartavtseva (eds.) Russkiy zhestovyy yazyk: zakonodatel'stvo, issledovaniya, obrazovanie [Russian Sign Language: Legislation, Research, Education]. Krasnoyarsk: KGPU im. Astaf'eva: 15-22.

Varinova O. A., Traul'ko E.V. (2011) Surdoperevod kak neobkhodimoe uslovie kachestvennogo professional'nogo obrazovaniya lits s narusheniem slukha [Sign Language Translation as a Necessary Condition for High-quality Vocational Education of People with Hearing Impairment]. Sovremennye issledovaniya sotsial'nykh problem [Modern Studies of Social Problems], $6(2): 21-23$. 